\title{
English and Chinese Humorous Languages under the Heterogeneous Domain Valve of Eastern and Western Culture
}

\author{
Jiayuan Chen ${ }^{*}$, Jia Gao \\ ${ }^{1}$ Department of English, School of Foreign Languages, Northwest University, Xi'an, China \\ ${ }^{2}$ Department of English, School of Foreign Languages, Guizhou Normal University, Guiyang, China \\ Email: *violette.chen@foxmail.com
}

How to cite this paper: Chen, J.Y. and Gao, J. (2019) English and Chinese Humorous Languages under the Heterogeneous Domain Valve of Eastern and Western Culture. Open Journal of Social Sciences, 7, 110-117.

https://doi.org/10.4236/jss.2019.72008

Received: January 13, 2019

Accepted: February 10, 2019

Published: February 13, 2019

Copyright $\odot 2019$ by author(s) and Scientific Research Publishing Inc. This work is licensed under the Creative Commons Attribution International License (CC BY 4.0).

http://creativecommons.org/licenses/by/4.0/

\begin{abstract}
From ancient times to the present, both language and writing have evolved along with the development of human society. When the culture of language develops to an inevitable stage, it will inevitably produce humor in the language. Humor itself is attached to language, which is a special part of language expression and conveyance. This paper will study the commonalities and differences of humorous speech acts in English and Chinese from the perspectives of pragmatics and intercultural communication, as well as the reasons for commonalities and differences. As we all know, there are huge differences between Eastern and Western civilizations. From the contrast between English and Chinese, it is clear that the humor elements are the same. Taking cultural background as the basis of research, it cuts into two comparison points in the way of thinking and expression from a number of different dimensions, and analyzes the humorous differences between English and Chinese in a deeper level. As a result, communication and translation barriers between the two languages are reduced.
\end{abstract}

\section{Keywords}

Humorous Language, Cultural Background, Expressions

\section{Introduction}

When the atmosphere is not harmonious, it will make people feel embarrassed, and humor can successfully adjust this unpleasant atmosphere, so that people can communicate smoothly. On the one hand, high-level humor will be remembered, and on the other hand, the truth is worthy of being interpreted [1]. Humor is a very important form of language expression. It not only reflects one's 
wisdom, but also the crystallization of the wisdom of the country and the nation. It is born in the long history of the nation's development. At the same time, in different periods and in different regions, humor can express people's life from a certain level. Nowadays, society can no longer leave the use of the language element of humor. When you feel tense in life, humor can successfully adjust life; when you feel a low mood, humor can ignite enthusiasm, and humor itself conveys a positive attitude. Humor is a unique language expression art that can be widely used in different historical and cultural backgrounds [2].

\section{Humor and Speech Act Theory}

Humor involves many fields. Since ancient times, scholars have conducted in-depth research on humor from many fields. Until the end of the 1970s, with the vigorous development of the economy and society, the field of linguistics began to occupy an important position in the study of English humor. Linguists' great attention to humor research makes Western language theory more perfect and richer [3]. Although Western speech act theory is extremely mature, it is undeniable that there are still deficiencies, and it is difficult to apply to all human languages. To this end, linguists actively introduce sociolinguistics and intercultural communication theory to further understand and analyze the correlation between language and culture under the premise of studying humor theory research [4].

\section{Differences in Humor between English and Chinese}

\subsection{Difference Caused by History and Culture}

The difference between English and Chinese humor is largely due to the differences in history and culture between the two places. Obviously, China is a landlocked country and a self-sufficient natural economy. The special history and culture make Chinese humor more restrained, more rigorous and realistic [5]. Our humor is more intelligent and contains profound philosophies. Like some fables, in t China's century-old long history, these humorous cultures are continually continued, and they all shine with wisdom. British humor originated in the ocean island countries with a lack of resources, and the terrible natural environment forced them to sail and find a better habitat. Therefore, they are relatively free-spirited and do not stick to the form of humor. Therefore, there is a big difference between British humor and Chinese humor [6].

\subsection{Difference Caused by Traditional Customs}

Just as art comes from life, humor comes from the bits and pieces of people's daily lives. English and Chinese humor can easily make readers feel the social customs unique to the nation. The Chinese Confucianism advocates the preservation of justice while annihilate desire. Humor related to sex is avoided and even a frightening topic in China [7]. Compared with the West, the West has far more humor in this respect than the Eastern humor, and the humor in the 
Western sexual theme occupies a large proportion.

\subsection{Difference Caused by Different Thinking Mode}

Chinese people pay attention to pragmatism, so Chinese-style humor is not simply for entertainment but gives humor more important historical mission attributes. At this level, Chinese humor is mostly ironic in social reality, and is largely due to the critical thinking way of the Chinese [8]. The people of Europe and the United States are free and unrestrained, and the humor is unloading the burden of criticism, but simply for entertainment.

\section{Reasons for the Differences between English and Chinese Humorous Languages in Specific Category}

\subsection{Object and Content}

The scope of English humor is far wider than Chinese humor mainly because China has long been in a feudal society. The whole society pursues three principles and five regularities, the ranks are strict, and the young and the young are well-ordered, which limits the object of Chinese humor to a large extent. In ancient times, it was difficult to see the king and the elders as humorous objects [9]. Even if they expressed good intentions, they did not dare to express them directly, but expressed them with the help of small people. Kings and feudal aristocrats are not willing to be treated as humorous objects. Once someone has published them as humorous objects, they will be brutally suppressed. In addition, religious beliefs are also sacred in China, and religious beliefs are never allowed to be considered humorous. In the West, there are many humorous works about the emperors and nobles, such as the emperor's new clothes. Of course, religion is also the object of humor in Europe and the United States. God is a humorous object, even dating back to ancient Greece, and humorous works about Christianity can be seen everywhere.

There are huge differences in the humor content between the East and the West. For example, the above mentioned on the topic of sex is a blank field in China, but it is an inseparable topic in Europe and the United States. Most of China's humorous subjects come from short parents, but they are thought-provoking and intriguing. The characteristics of our humorousness are seen by the ambassadors. For example, the sword is a small story, but it gives us a profound and profound revelation. The theme of Western stories can be large or small, and there is no clear distinction. Diversity is an important feature of Western humor. It can be seen that the two are still quite different in humor content [10].

\subsection{Purpose}

Although there are huge differences between English and Chinese humor, it is undeniable that there is a commonality between the two, which is to express the author's thoughts. This commonality is deeply contained in humor. As mentioned above, an important attribute of Chinese humor is the awkwardness, so 
the purpose of Chinese humor is clearer. For example, Premier Zhou's long story is very humorous. It is very wise to turn the reporter's question about the road into a path of Marxism. It not only shows the wisdom of the Chinese leader but also shows his political position. In the West, on the contrary, Western humor is purely for entertainment, and there is very little trade thinking. It is just to relax the body and mind, and to feel the mood. At this point, the difference between English and Chinese humor can be clearly seen.

\subsection{Features}

The humorous ways of different languages are deeply influenced by the historical environment and the soil of native culture. From one perspective, the humor of English language has certain convergence with the cultural characteristics of English-speaking countries. The expression of English-speaking countries is more direct, reflected in the humorous way, which also means that English has a strong irony and a strong offensive power. Different from Chinese culture, which advocates euphemism and mystery, Chinese humor is also more implicit. Its pragmatic meaning is usually to express ideas indirectly to achieve the purpose of expressing feelings and interpersonal harmony. This of course does not rule out the aggressiveness of Chinese in individual situations [11]. In summary, in general, the oriental culture represented by China emphasizes implicit euphemism in a humorous way, while the Western culture represented by the English-speaking country is straightforward in terms of humor. This can be seen in the daily use of Chinese. Chinese people often like to use "one" to refer to and insinuate their true target individuals, avoiding direct confrontation. This expression of Chinese reflects the long history and profoundness of Chinese culture from one aspect. The direct and explicit humor of English also makes people feel impressed and impressed.

\section{Rhetorical Skills}

\subsection{Pun}

Pun's rhetorical skills are relative to the same language environment. It makes words with multi-syllable and polysyllabic words or homophonic or homophonic words applied in a certain context, and makes the statement ambiguous, giving the listener different meanings, so that the language expression is more euphemistic. At the same time, it also plays a certain humorous effect, and easily resolves the embarrassment of dialogue. This rhetorical technique can be divided into two parts: semantic pun and pronunciation pun or homophonic pun. These two rhetorical techniques are also common in English language culture and Chinese language culture [12].

1) Semantic Pun

The word pun, as the name implies, is based on a variety of target words with different contexts and contextual connections with diverse meanings, and a variety of ways of understanding in the context. For example, the well-known Da- 
bao advertising word "If you want good skin, use Dabao in the morning and evening", the "morning and evening" here is a typical and representative embodiment of the word pun. The most superficial meaning of "morning and evening" is the abbreviation and abbreviation for "morning and evening." In Chinese, and even in a wider range of usages, it is synonymous with "sooner or later". In this way, the application of the word pun gives this advertisement a more humorous and vivid expression, which makes the advertising word more deeply rooted in the hearts of the people and realizes the effect of the company promoting the product. Similarly, in English advertisements, for example, the usage of "pretty" is used as the meaning of the word pun according to the difference in part of speech in different scenes (the adjective means "pretty" and the adverb means "equivalent").

2) Pronunciation Pun

The pronunciation pun is based on the same or similar pronunciation of different words, and is placed in the whole sentence to produce a variety of understanding ways to form a humorous effect that makes people laugh. For example, the usage of "bronchitis" in Chinese, because of its homophonic "shoulders strict", is the use of the phenomenon of pronunciation pun to achieve a witty effect. Similarly, in English, the use of such rhetorical devices is more common. For example, in the phone scene, the similarity between the "What" and the name "Watt"; the "not" and the name "Knott" are even the same. Sexuality has produced ambiguous effects and formed misunderstandings in communication, thus achieving humorous effects. It is hard to read [13].

Through the above examples, we can clearly see the important value of pun in expressing humor in English and Chinese.

\subsection{Irony}

The irony is to convey the meaning of the intention and the thought, with more or less ridicule and irony, by using the opposite of the original meaning. Its functional utility is to express a sense of humor while conveying satire, so many situations of irony are more penetrating than positive speech, e.g.:

Xi Yu Jia Qin Zhuan Hou Si

Chu Mao Ye Shou Shi Xian Sheng

The above couplet is a conversational exchange between Pu Songling and his private wife Mr. Shi. Rumors that one day, the stone surname teacher smashed the bird that was raised by Pu Songling, and then placed it in the same place, sealed it with stones, and wrote a sentence on the wall next to it:

Xi Yu Jia Qin Zhuan Hou Si

When Pu Songling surprisingly found that the bird he was feeding had died for no reason, and then saw the sentence written on the wall, it was clear that it was Mr.'s masterpiece, and then the second half:

Chu Mao Ye Shou Shi Xian Sheng

$\mathrm{Mr}$. Shi knew that he was angry and rushed to the crown, and found that $\mathrm{Pu}$ 
Songling tried to get back to justice. When he saw it, Pu Songling was very calm and returned to his teacher on the grounds of purely couplet. The teacher then quietly thought about it and realized that the irony used in it was right. It should be said that it was quite right. Mr. Shi was speechless for a time. This vivid little story became witty and funny because of the irony. In English, irony is also more commonly used in the expression of humor, such as: As we all know, the storm is unpopular. Usually, no one likes the storm. In English, it is often inclined to use the storm to express the meaning of "unpopular", namely "As welcome as storm". Therefore, the proficient use of irony can make everyday communication more interesting.

\subsection{Exaggeration}

Exaggerated rhetoric is a very common rhetorical device in life. Exaggerated rhetoric often emphasizes and strengthens a particular link by exaggerating the plot of the event, which can often lead to humor. Exaggerated rhetoric can often achieve unexpected results, such as the little boy closely behind a fat lady, the fat lady asked why, the little boy said that he used to walk in the shade. Both Chinese and Western humor often use exaggeration to trigger humor, because exaggerated techniques can render and enhance comedy effects well.

In the same way as English, English-speaking people often use exaggerated rhetoric to create a sense of humor. For example, when a husband is chatting with a colleague, when a colleague asks her husband how the weekend is going, the husband replies that he has been painting the wall for his wife all weekend. The colleague then asks, "Does she do that often?", Husband responded humorously to her colleagues. Five years ago, his family had nine rooms "nine by twelve", and now there are only eight rooms "eight by eleven".

In this story, when the husband answered his colleague's question, he exaggerated that his wife had brushed the wall, and the two rooms were connected [14]. He humorously conveyed his wife's excessive enthusiasm for painting the walls, while at the same time euphemistically and courteously criticized his wife.

\subsection{Metaphor}

Metaphor is also a common rhetorical technique. Of course, it is also common in humor. In Chinese, animals are used to describe people, and they often achieve the humorous effect of the image. For example, the pig teammates are stupid as the action partners, and the cows are more capable of describing people and achieve extremely interesting humor effects.

The West also uses metaphors to enhance humor, such as As mad as March hare, which means crazy like a March rabbit, or as sly as a fox, like a fox. These European and American proverbs are very humorous, and it is extremely interesting to compare a person to a crazy rabbit.

\subsection{End Rhyme}

The rhyme is the same as the ending vowels of two or more words and the con- 
sonants that follow. In the English and Chinese, people often use the rhyme of the rhyme to enhance the humor of the language. In many of Chinese essays, the difference in tail vowels is often used to create some comedy clashes, and these comets have different comedy effects. For example, Zhao Lirong and Gong Hanlin's essay "Kung Fu" skillfully used the "song" and "onion" tail rhymes, which naturally produced the humorous effect of the language. In English, "dreaming" and "screaming" are usually pronounced in the same tail of the word to produce a very humorous language effect.

The end rhyme is the common language skill of English and Chinese humor.

\section{Conclusion}

Comparing Chinese and Western cultures, it can be clearly seen that both the historical background and the way of thinking are completely different. In the language of humor, the meaning and form are different. After a long history of 5000 years of Chinese history, the humor of its language art has become culturally connotated after a generation of inheritance and accumulation. Many humorous contents have become a classic because of their great wisdom, and they have been widely circulated. These humors not only play an entertaining role in people's lives and work, but also alert everyone [15]. The generation of humor in English is relatively more casual than Chinese humor. It does not require a specific language environment, and it does not pay much attention to the occasion. It only needs to be reasonable and can produce humor. Viewing humorous issues from different cultural perspectives has an extremely important impact on the study of language and culture. Of course, it can also enrich the theory of language use, and it has extremely important guiding value for various fields. At present, cultural exchanges are becoming more frequent in the context of economic globalization. The study of humorous culture in English and Chinese will greatly promote the elimination of cultural barriers in different regions of the world, promote better cultural exchanges and break the barriers of cultural exchanges.

\section{Conflicts of Interest}

The authors declare no conflicts of interest regarding the publication of this paper.

\section{References}

[1] Chen, S.H. (1990) English Rhetoric and Translation. Beijing University of Posts and Telecommunications Press, Beijing.

[2] Hu, F.Z. (1987) Humorous Linguistics. Shanghai Academy of Social Sciences Press, Shanghai.

[3] Li, J.H. (1996) Humorous Language. Social Sciences Academic Press, Beijing.

[4] Attardo, S. (1994) Linguistic Theories of Humor. Mouton de Gruyter, Berlin/New York.

[5] Austin, J.L. (2002) How to Do Things with Words. Foreign Language Teaching and 
Research Press, Beijing.

[6] Searle, J.R. (1969) Speech Acts. Cambridge University Press, Cambridge. https://doi.org/10.1017/CBO9781139173438

[7] Deng, Y.C. and Liu, R.Q. (1991) Language and Culture-English-Chinese Language Comparison. Foreign Language Teaching and Research Press, Beijing.

[8] Nature, H. (1998) Introduction to Pragmatics. Hunan Education Press, Changsha.

[9] Li, Y.F. (2004) Pragmatic Analysis of Verbal Humor. Journal of Liaocheng Humanities (Social Science Edition), No. 2.

[10] Liu, R.Q. (1998) The School of Western Linguistics. Foreign Language Teaching and Research Press, Beijing.

[11] Chen, L.S. and Chen, S. (1993) Foreign Humor Story Collection • Celebrity Humor. Shanghai Knowledge Publishing House, Shanghai.

[12] Ersanli, Y. (2017) Developing Pre-Service English Language Teachers' Comprehension of Texts with Humorous Elements. Journal of Language \& Linguistic Studies, No. 13.

[13] Yan, Z. (2006) A Comparison between Chinese and English Humorous Utterances. US-China Foreign Language, 4, 54-66.

[14] Qu, Y.Y. and Zhou, Y.M. (2012) Application of Pragmatic Theories on Humorous Language in Advertisement and their Translation. Campus English (Teaching and Research), 9, 105-108.

[15] Zhang, L.H. (2012) A Linguistic Analysis of Humorous Discourses between the English and Mandarin Language. Overseas English, 4, 253-255. 